\title{
Aberrant expression of epithelial and neuroendocrine markers in alveolar rhabdomyosarcoma: a potentially serious diagnostic pitfall
}

\author{
Armita Bahrami ${ }^{1}$, Allen M Gown ${ }^{2}$, Geoffrey S Baird ${ }^{2}$, M John Hicks ${ }^{1}$ and Andrew L Folpe ${ }^{3}$ \\ ${ }^{1}$ Texas Children's Hospital and Baylor College of Medicine, Houston, TX, USA; ${ }^{2}$ Phenopath Laboratories, \\ Seattle, WA, USA and ${ }^{3}$ Mayo Clinic, Rochester, MN, USA
}

\begin{abstract}
Alveolar rhabdomyosarcoma may be extremely difficult to distinguish from other primitive round cell neoplasms without ancillary immunohistochemistry and/or genetic study. Particularly in adults and in the head and neck locations, the differential diagnosis of alveolar rhabdomyosarcoma includes small cell carcinoma and neuroepithelial tumors, such as esthesioneuroblastoma. We have recently seen cases of genetically confirmed alveolar rhabdomyosarcoma, which were misdiagnosed owing to expression of cytokeratins and neuroendocrine markers. We studied a large group of well-characterized alveolar rhabdomyosarcomas for expression of such markers. Forty-four alveolar rhabdomyosarcomas (18 genetically confirmed) were retrieved from our archives and immunostained for wide-spectrum cytokeratin (OSCAR), low molecular weight cytokeratin (Cam5.2), synaptophysin, chromogranin A, and CD56 using commercially available antibodies. Cases were scored as 'negative', 'rare' ( $<5 \%$ positive cells), ' $1+$ ' ' $(5-25 \%)$, ' $2+$ ' ' $(26-50 \%)$ and ' $3+$ ' $(>51 \%)$. The tumors occurred in 23 males and 21 females at a mean age of 18 years (range, $<1-64$ years), and involved many sites. Fifty percent of cases (22 of 44) expressed wide-spectrum cytokeratin, and scored almost equally as rare, $1+$, and $2+$, but rarely $3+$. Cam5.2 was positive in $52 \%$ (14 of 27). Forty-three percent of cases (16 of 37) expressed at least one of the specific neuroendocrine markers, $32 \%$ (12 of 37) expressed synaptophysin, 22\% (eight of 36 ) expressed chromogranin A, and $11 \%$ expressed both. Expression of synaptophysin and chromogranin A was typically confined to rare cells but could be more widespread. Thirty-two percent of cases (12 of 37) expressed the wide-spectrum cytokeratin and at least one of the neuroendocrine markers, and $8 \%$ (three of 36 ) expressed cytokeratin and both neuroendocrine markers. CD56 expression was nearly ubiquitous. Aberrant expression of epithelial and neuroendocrine markers is relatively common in alveolar rhabdomyosarcoma, occurring in $30-40 \%$ of cases. These findings have significant implications for the diagnosis of alveolar rhabdomyosarcoma, particularly in adults and in the head and neck locations. Although expression of cytokeratin and/or synaptophysin alone does not necessarily indicate epithelial or neuroendocrine differentiation, coexpression of cytokeratin and neuroendocrine markers, and in particular the presence of chromogranin expression, suggest true epithelial and/or neuroendocrine differentiation in a subset of alveolar rhabdomyosarcomas. CD56 is not a specific neuroendocrine marker, and should not be used in the absence of synaptophysin/chromogranin. These findings emphasize the need to employ a panel of markers, to include desmin, myogenin/MyoD1, and genetic study in the diagnosis of primitive round cell neoplasms in all age groups and in all locations.
\end{abstract}

Modern Pathology (2008) 21, 795-806; doi:10.1038/modpathol.2008.86; published online 16 May 2008

Keywords: alveolar rhabdomyosarcoma; immunohistochemistry; cytokeratins; synaptophysin; chromogranin A; molecular genetics

Correspondence: Dr AL Folpe, MD, Department of Laboratory Medicine and Pathology, Mayo Clinic, 200 1st Street SW, Rochester, MN 55905, USA.

E-mail: Folpe.Andrew@Mayo.edu

Received 18 February 2008; revised 08 April 2008; accepted 14

April 2008; published online 16 May 2008
Alveolar rhabdomyosarcoma is a primitive sarcoma which exhibits limited skeletal muscle differentiation at the light microscopic and ultrastructural level. ${ }^{1,2}$ Alveolar rhabdomyosarcomas most often occur in older children, with a median patient age of between 7 and 9 years, but are also relatively common in adolescents and young adults, and may 
rarely involve even elderly patients. ${ }^{3-5}$ Although alveolar rhabdomyosarcoma was initially thought to be principally a tumor of the extremities, subsequent series have shown an equal occurrence in head and neck locations, including the orbit, sinuses and ear. ${ }^{3,6-8}$ In its classic form, alveolar rhabdomyosarcoma is comprised of distinctive nests of primitive-appearing round cells, which grow in a discohesive fashion, surrounded by hyalinized and highly vascular fibrous septae, producing a pseudoalveolar pattern. ${ }^{3-5}$ Obvious rhabdomyoblastic differentiation, in the form of strap cells and cells with cross striations is seldom identified. Solid forms of alveolar rhabdomyosarcomas lack the prominent nested pattern and cellular discohesion seen in classic alveolar rhabdomyosarcomas and may closely mimic a variety of other 'small round cell tumors'.9,10

By immunohistochemistry, alveolar rhabdomyosarcomas typically express vimentin, desmin, muscle actins (including smooth muscle isoforms), myogenin, and MyoD1. ${ }^{11-29}$ Myogenin and MyoD1, two of the myogenic transcriptional regulatory proteins, are highly sensitive and are specific markers of rhabdomyoblastic differentiation. ${ }^{30,31} \mathrm{In}$ general, myogenin expression is uniform and intense in alveolar rhabdomyosarcoma and somewhat more patchy and weak in embryonal rhabdomyosarcoma. ${ }^{15}$ At the genetic level, alveolar rhabdomyosarcomas are characterized in nearly $80 \%$ of cases by one of two specific translocations, $\mathrm{t}(2 ; 13)(\mathrm{q} 35 ; \mathrm{q} 14)$, found in approximately $60 \%$ of cases, or $\mathrm{t}(1 ; 13)(\mathrm{p} 36 ; \mathrm{q} 14)$, found in approximately $20 \%$ of cases. $^{32,33}$ The $t(2 ; 13)$ results in fusion of the $P A X 3$ gene on chromosome 2 to the FKHR (FOX$O 1 A)$ gene on chromosome 13 , whereas the $t(1 ; 13)$ results in fusion of the $P A X 7$ gene on chromosome 1 to the FKHR gene. ${ }^{32,33}$ These gene fusions may be demonstrated by traditional cytogenetics, RT-PCR or FISH, and are specific for alveolar rhabdomyosarcoma, allowing its distinction from other round cell sarcomas. ${ }^{33,34}$

Alveolar rhabdomyosarcomas are aggressive sarcomas, which carry a poor prognosis and require histiotype-specific therapy. Thus, the accurate diagnosis of alveolar rhabdomyosarcoma and its distinction from other small round cell tumors is of great clinical significance. Recently, in our consultation practices, we have seen a small number of alveolar rhabdomyosarcomas which were initially confused with neuroendocrine carcinomas or desmoplastic small round cell tumor, owing to expression of cytokeratins and neuroendocrine markers, such as synaptophysin and chromogranin A. To determine the frequency of this aberrant immunohistochemical phenotype, and to raise awareness of this potentially serious diagnostic pitfall, we undertook a retrospective immunohistochemical study of epithelial and neuroendocrine markers in a well-characterized series of alveolar rhabdomyosarcomas.

\section{Materials and methods}

The pathology archives at our institutions (Mayo Clinic, Rochester, MN; Texas Children's Hospital, Houston, TX; and PhenoPath Laboratories, Seattle, WA, USA) were searched for surgical specimens diagnosed as alveolar rhabdomyosarcoma. A total of 44 cases diagnosed as alveolar rhabdomyosarcoma (42 cases) or mixed alveolar and embryonal rhabdomyosarcoma (two cases) were retrieved. The pathology reports and all available hematoxylin and eosin-stained and immunohistochemical slides were re-reviewed and the diagnoses confirmed. All cases were positive for myogenin or MyoD1. Previous cytogenetic and/or molecular genetic study, performed in 19 cases during their initial diagnostic evaluation, confirmed the presence of alveolar rhabdomyosarcoma associated fusion transcripts in 18 cases, including $P A X 3 / F K H R$ (nine cases) and $P A X 7 / F K H R$ (four cases). In five cases the RT-PCR result had been reported simply as 'positive for $P A X 3 / F K H R$ or $P A X 7 / F K H R$ fusion transcript'. The previously evaluated mixed alveolar and embryonal rhabdomyosarcoma was negative for both fusion genes.

For immunohistochemistry, 4- $\mu \mathrm{m}$ sections of formalin-fixed paraffinized tissue were immunostained using commercially available antibodies against wide-spectrum cytokeratins (clone OSCAR, 1:200), low molecular weight cytokeratins (clone Cam5.2, 1:150), synaptophysin (clone SY38, 1:40 and clone SNP88, 1:250), chromogranin A (clone LK2H10, 1:500), and CD56 (clone 123C3, 1:25), using heatinduced epitope retrieval and the DAKO Envision detection system. Not all cases contained sufficient tissue for all studies; overall wide-spectrum cytokeratin was performed in 44 cases, low molecular weight cytokeratin in 27 cases, synaptophysin in 37 cases, chromogranin A in 36 cases, and CD56 in 31 cases. The immunohistochemical results were semi-quantitatively scored as follows: $0 \%$ positive cells $=$ 'negative', $1-<5 \%$ positive cells $=$ 'rare cells', $5-25 \%$ positive cells = ' $1+$ ', $26-50 \%$ positive cells $=$ ' $2+$ ', and $>51 \%$ positive cells $=$ ' $3+$ '. The intensity of staining was not evaluated. For mixed tumors, only the alveolar component was evaluated and scored.

\section{Results}

\section{Clinicopathological Features}

Table 1 summarizes the clinicopathological features of the 44 cases of alveolar rhabdomyosarcoma. The tumors occurred in 23 males and 21 females, ranging from 7 months to 64 years of age (median, 14.5 years). The patients consisted of 15 children $<10$ years of age, 12 adolescents (10-18 years old), 13 young adults (19-44 years old), two middle aged adults (45-60 years old), and two older adults $>60$ years of age. The primary tumors were available for 
Table 1 Clinicopathological features

\begin{tabular}{|c|c|}
\hline Characteristics & No. of patients (\%) \\
\hline \multicolumn{2}{|l|}{ Age (years) } \\
\hline$<10$ & $15(34)$ \\
\hline $10-18$ & $12(27)$ \\
\hline $19-44$ & $13(30)$ \\
\hline $45-60$ & $2(4.5)$ \\
\hline$>60$ & $2(4.5)$ \\
\hline Total & $44(100)$ \\
\hline \multicolumn{2}{|l|}{ Gender } \\
\hline Male & $23(52)$ \\
\hline Female & $21(48)$ \\
\hline \multicolumn{2}{|l|}{ Tumor location } \\
\hline Primary site & $36(82)$ \\
\hline Head and Neck & $13(30)$ \\
\hline Upper extremity & $4(9)$ \\
\hline Lower extremity & $3(7)$ \\
\hline Trunk & $3(7)$ \\
\hline Breast & $2(4.5)$ \\
\hline Retroperitoneum & $2(4.5)$ \\
\hline Pelvis & $1(2)$ \\
\hline Perineum & $2(4.5)$ \\
\hline Genitourinary tract & $3(7)$ \\
\hline Abdomen & $2(4.5)$ \\
\hline Unknown & $1(2)$ \\
\hline Metastatic site & $8(18)$ \\
\hline Lymph node & 7 (16) \\
\hline Lung & $1(2)$ \\
\hline \multicolumn{2}{|l|}{ Histologic type } \\
\hline ARMS & $42(95.5)$ \\
\hline ARMS/ERMS & $2(4.5)$ \\
\hline \multicolumn{2}{|l|}{ Cytogenetic/molecular } \\
\hline PAX3/FKHR & $9(21)$ \\
\hline PAX7/FKHR & $4(9)$ \\
\hline Positive, not specified ${ }^{a}$ & $5(11)$ \\
\hline Negative & $1(2)^{\mathrm{b}}$ \\
\hline Not performed & $25(57)$ \\
\hline
\end{tabular}

ARMS, alveolar rhabdomyosarcoma; ARMS/ERMS, mixed alveolar and embryonal rhabdomyosarcoma; LN, Lymph node.

${ }^{a}$ Positive for $P A X 3 / F K H R$ or $P A X 7 / F K H R$ fusion transcript by RT-PCR.

${ }^{\mathrm{b}}$ A case of mixed ARMS/ERMS.

study in 36 cases; for eight patients only metastases (seven to lymph nodes, one to lung) were available. The 36 primary tumors arose in many sites, including the head and neck region (13 cases), upper extremity (four cases), lower extremity (three cases), trunk (three cases), breast (two cases), retroperitoneum (two cases), pelvis (one case), perineum (two cases), genitourinary tract (three cases), abdomen (two cases), and one unknown location.

\section{Immunohistochemical Results}

The immunohistochemical results are summarized in Table 2 and illustrated in Figures 1-4. Overall, approximately $50 \%$ of cases were positive for either wide-spectrum cytokeratins or low molecular weight cytokeratins, with the majority of positive cases showing 1-2+ staining. Four cases were wide-spectrum cytokeratin positive and low molecular weight cytokeratin negative, whereas two cases were wide-spectrum cytokeratin negative and low molecular weight cytokeratin positive.

Synaptophysin expression was seen in 12 of 37 cases $(32 \%)$, with the majority of positive cases showing rare cells to $1+$ positivity. One case was $3+$ positive for synaptophysin. Chromogranin A was expressed by eight of 36 cases (22\%), with the majority of cases again showing rare cells or $1+$ positivity. Coexpression of both synaptophysin and chromogranin A was seen in four of $36(11 \%)$ of cases, with 16 of 37 cases (43\%) showing expression of either marker.

Coexpression of cytokeratins (wide-spectrum or low molecular weight cytokeratins or both) and synaptophysin or chromogranin was seen in 12 of 37 cases $(32 \%)$. Coexpression of cytokeratins with synaptophysin and chromogranin was seen in three of 36 cases $(8 \%)$.

CD56 expression was nearly ubiquitous, with expression in 30 of 31 tested cases (97\%). CD56 was $3+$ in 25 of 30 positive cases $(83 \%)$.

No differences were seen in the immunohistochemical profiles of cases with and without genetic confirmation (data not shown).

\section{Discussion}

Mimicry of other small round cell tumors by alveolar rhabdomyosarcoma was recognized in Enzinger and Shiraki's seminal description of alveolar rhabdomyosarcoma in 1969, and emphasized in several subsequent reports. ${ }^{3,35,36}$ Although these early reports emphasized the use of then-available technologies, including careful light microscopic and later ultrastructural analysis, in the resolution of this often difficult differential diagnosis, there has been a dramatic shift towards the use of ancillary immunohistochemistry in this setting over the past two decades. Beginning in the late 1980s, with the recognition of the utility of immunohistochemistry for muscle actins and desmin in the distinction of alveolar rhabdomyosarcoma from other primitive malignant neoplasms, and continuing in the 1990s with the advent of immunohistochemistry for first MyoD1 and subsequently myogenin, immunohistochemistry has assumed a primary role in the diagnosis of alveolar rhabdomyosarcoma. ${ }^{15,35-37}$ With increasing use of immunohistochemistry, however, has come the recognition that the expression of many markers may be considerably more widespread than was initially thought, with expression of desmin, for example, now well recognized in a variety of non-myogenic neoplasms, such as Ewing sarcoma/ primitive neuroectodermal tumor, $^{38}$ ossifying fibromyxoid tumor, ${ }^{39}$ and angiomatoid (malignant) fibrous histiocytoma, ${ }^{40}$ among others. Similarly, expression of putative epithelial markers, such as 
Table 2 Immunohistochemical results

\begin{tabular}{|c|c|c|c|c|c|}
\hline Score & WSCK & $L M W C K$ & Chromogranin $A$ & Synaptophysin & $C D 56$ \\
\hline Negative & 22 & 13 & 28 & 25 & 1 \\
\hline Rare $^{*}$ & 7 & 4 & 5 & 8 & 0 \\
\hline $1+^{*}$ & 6 & 6 & 3 & 3 & 1 \\
\hline $2+{ }^{*}$ & 8 & 4 & 0 & 0 & 4 \\
\hline $3+^{*}$ & 1 & 0 & 0 & 1 & 25 \\
\hline Overall (+) & $22 / 44(50 \%)$ & $14 / 27(52 \%)$ & $8 / 36(22 \%)$ & $12 / 37(32 \%)$ & $30 / 31(97 \%)$ \\
\hline
\end{tabular}

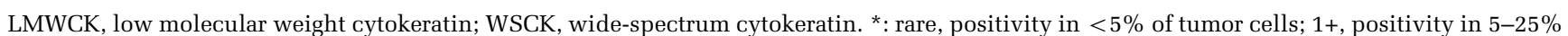
of tumor cells; $2+$, positivity in $26-50 \%$ of tumor cells; $3+$, diffuse positivity in $51 \%$ or more of tumor cells.

cytokeratins, has now been recognized to occur in a variety of neoplasms apparently lacking epithelial differentiation, including angiosarcoma, ${ }^{41}$ leiomyosarcoma, ${ }^{42}$ Ewing sarcoma/primitive neuroectodermal tumor, ${ }^{43}$ and schwannoma. ${ }^{44}$

In the present study, we have identified relatively frequent expression of cytokeratins and neuroendocrine markers in 42 pure alveolar rhabdomyosarcoma and two mixed alveolar and embryonal rhabdomyosarcoma, including 18 genetically confirmed alveolar rhabdomyosarcomas. Overall, approximately $50 \%$ of cases showed at least rare cytokeratin-positive cells, strongly suggesting that anomalous cytokeratin expression is significantly more common in alveolar rhabdomyosarcoma than has been recognized. Similarly, expression of at least one neuroendocrine marker was noted in over $40 \%$ of cases, clearly implying that aberrant neuroendocrine marker expression is more widespread than has been appreciated. Perhaps most interestingly, coexpression of epithelial and neuroendocrine markers and coexpression of multiple neuroendocrine markers were present in approximately $10 \%$ of cases, suggesting that a subset of alveolar rhabdomyosarcoma may in fact show true epithelial and/or neuroendocrine differentiation.

The demographic features of the alveolar rhabdomyosarcoma in the present study are very comparable to previously reported cases, with regards to patient age, sex and tumor location, suggesting that our results are generally applicable to all alveolar rhabdomyosarcomas. Furthermore, we did not identify any significant association between expression of epithelial and/or neuroendocrine markers and any demographic parameter (data not shown), implying that expression of such markers is not confined to a unique subgroup of alveolar rhabdomyosarcoma, such as tumors arising in the head/ neck. Finally, no differences in expression patterns were noted between genetically confirmed and nonconfirmed cases. We therefore believe these results have significant implications for the diagnosis of alveolar rhabdomyosarcoma in any location and patient group, but are particularly significant in adult patients and in locations where epithelial and neuroendocrine neoplasms are far more common than are alveolar rhabdomyosarcoma, such as the head/neck.
The cytokeratins are the most complex members of the intermediate filament protein family, consisting of more than 20 proteins. The cytokeratins may be grouped by their molecular weights, into acidic and basic subfamilies, or by their usual pattern of expression in simple or complex epithelium. In practice, the cytokeratins are most commonly thought of in terms of low molecular weight cytokeratins (cytokeratins 8, 18, and 19) and high molecular weight cytokeratins (cytokeratins 1, 5, 10, and 14). Monoclonal antibody OSCAR is a recently developed reagent raised against cytokeratin extracts from a carcinoma cell line. Our personal experience with this antibody has suggested that it is a highly sensitive wide-spectrum cytokeratin antibody, equalling or surpassing the sensitivity of more widely utilized markers, such as the AE1/AE3 cocktail (Andrew L Folpe and Allen M Gown, personal observations). In normal tissues, OSCAR appears to recognize all cytokeratin-positive cells, with the exception of the superficial layers of the epidermis (most likely reflecting non-reactivity with high molecular weight cytokeratins 1 and 10). Monoclonal antibody Cam5.2 recognizes the low molecular weight cytokeratins 8 and 18 (and possibly 19). We chose to use these two antibodies in this study to maximize the possibility of detecting anomalous cytokeratin expression in alveolar rhabdomyosarcoma. Although a direct comparison of the relative frequency of anomalous cytokeratin immunoreactivity in alveolar rhabdomyosarcoma with different wide-spectrum cytokeratin antibodies, such as AE1/AE3 or MNF116, is beyond the scope of this study; we would note that we have seen such cases in consultation from outside laboratories that have used these antibodies. Additionally, our finding of similar rates of cytokeratin expression using two different antibodies argues against the possibility that these findings represent cross-reactivity of either OSCAR or Cam5.2 with epitopes on noncytokeratin proteins.

Although expression of cytokeratins was initially regarded as specific for epithelial cells, it has become abundantly clear over the past two decades that cytokeratin expression is not restricted to carcinomas. Among the small round cell tumors, desmoplastic small round cell tumor and Wilms tumor routinely express cytokeratins, ${ }^{45,46}$ and 

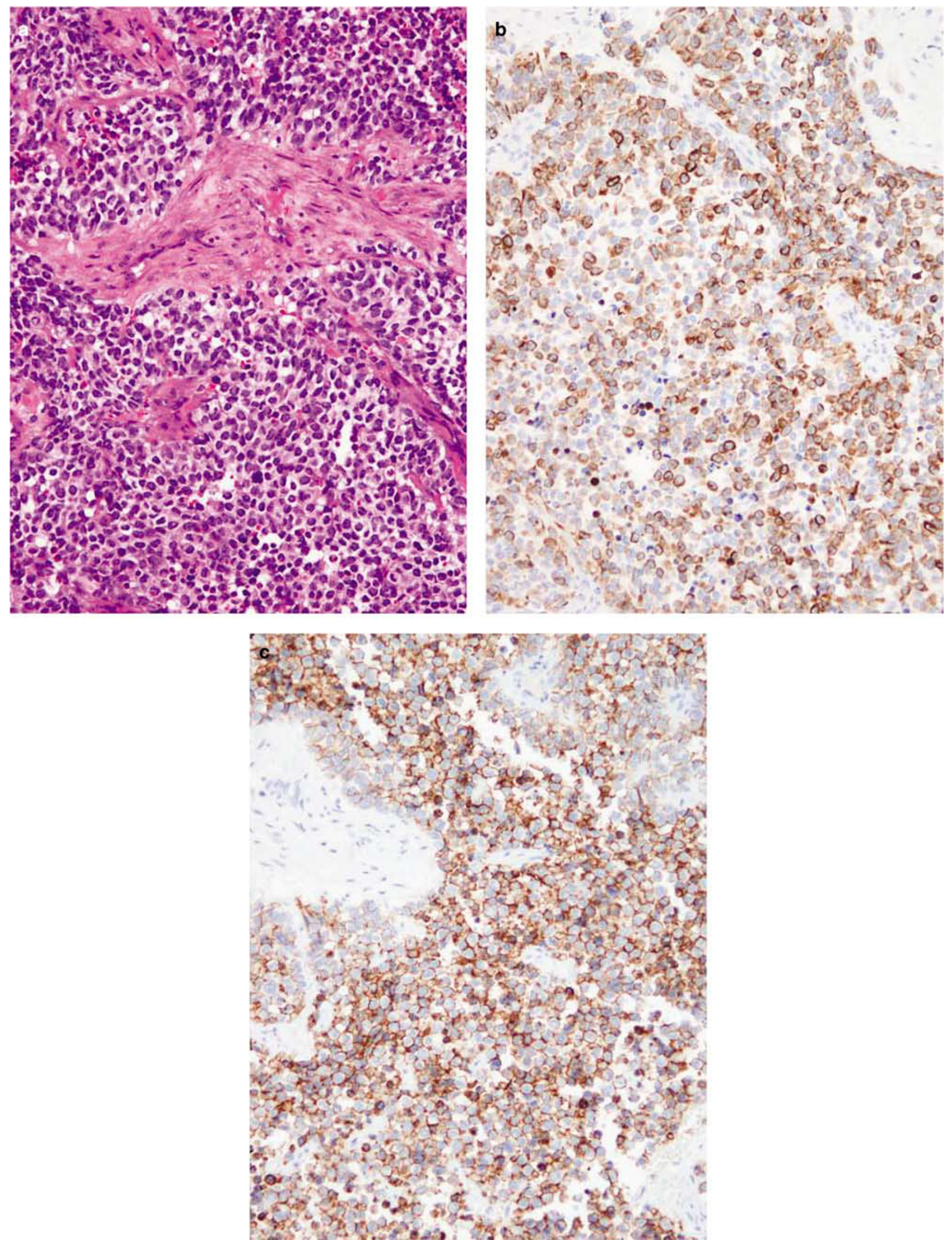

Figure 1 Alveolar rhabdomyosarcoma (a) diffusely positive for wide-spectrum cytokeratin (b) and CD56 (c). 
800
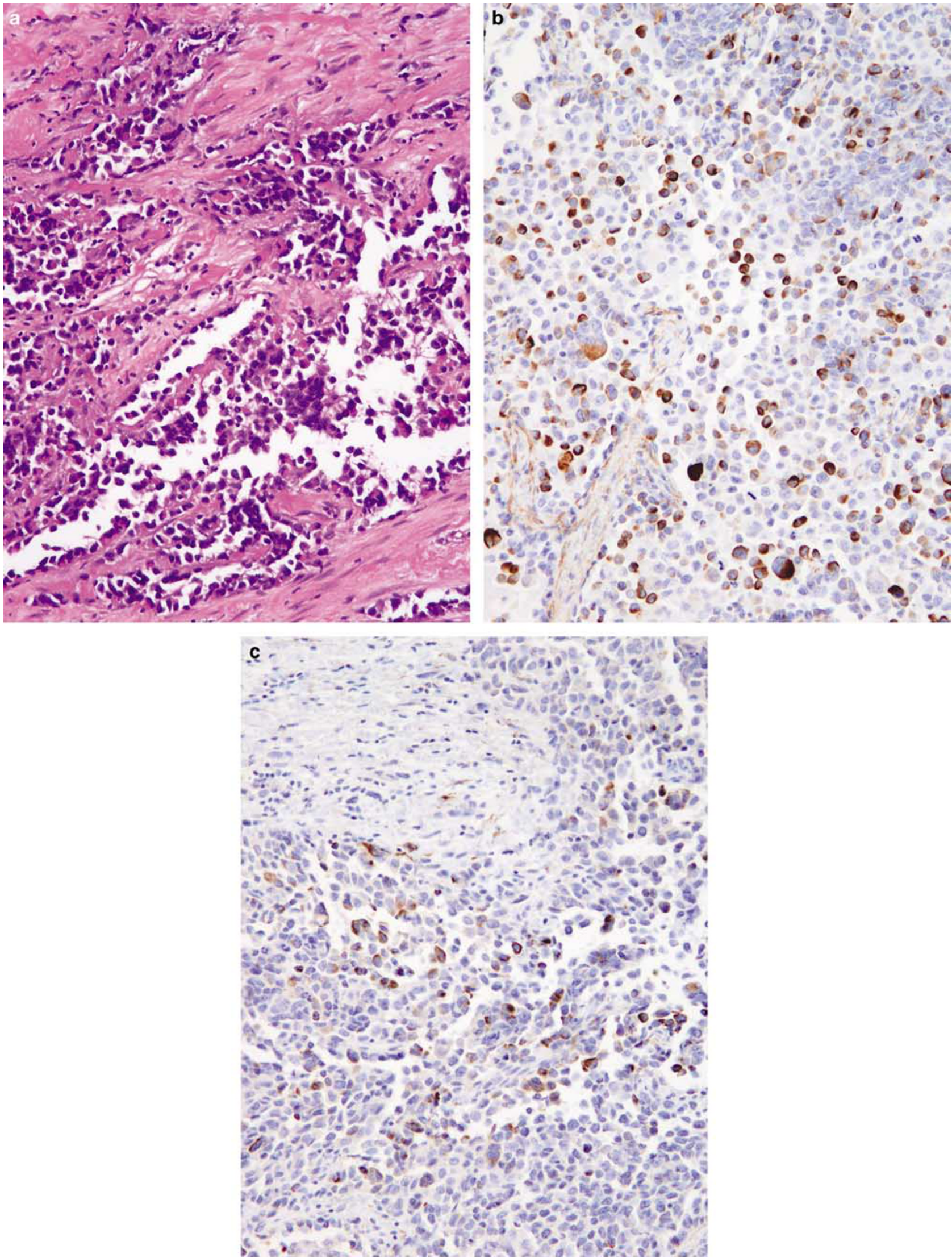

Figure 2 Alveolar rhabdomyosarcoma (a) positive for both wide-spectrum cytokeratin (b) and low molecular weight cytokeratin (c). 

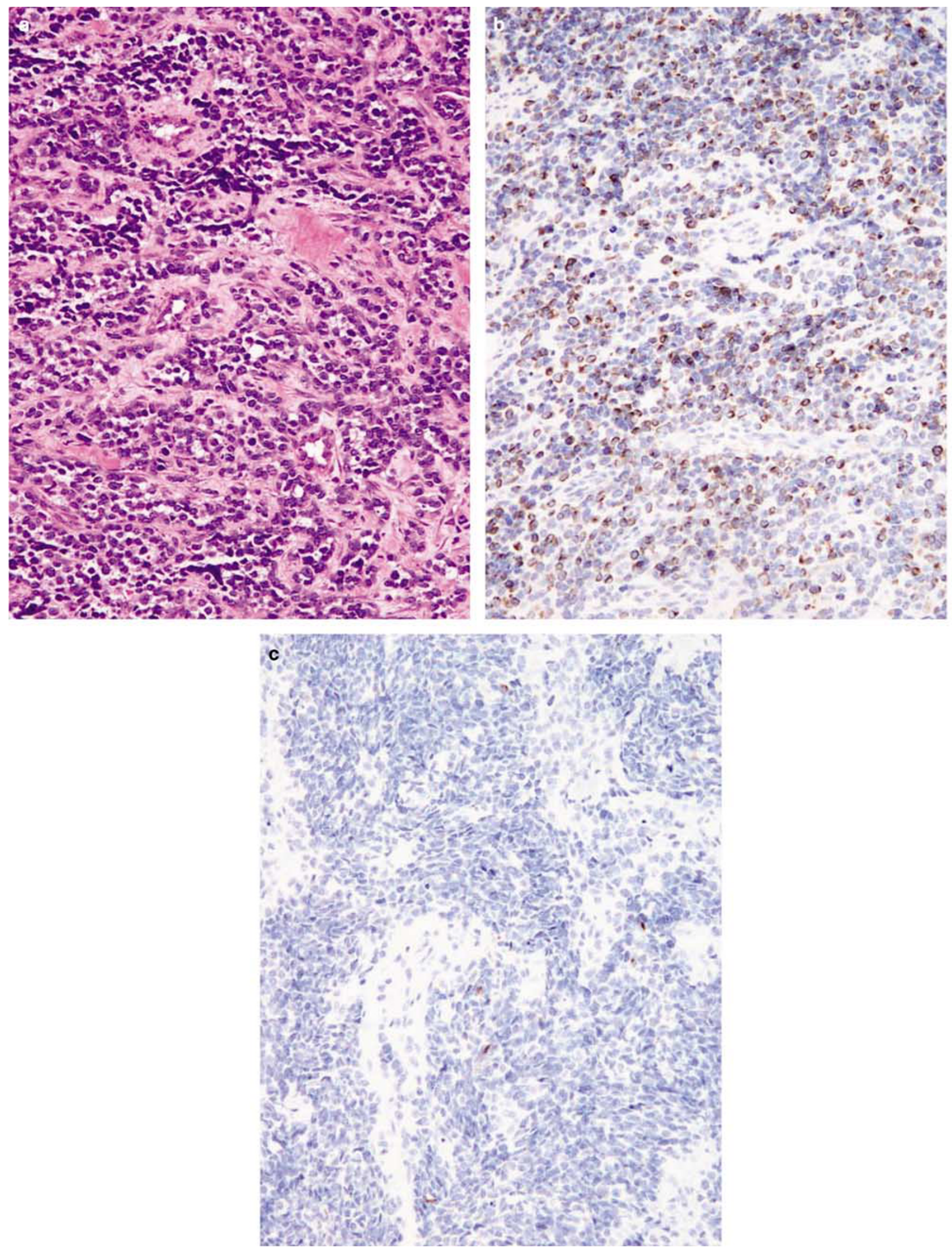

Figure 3 Alveolar rhabdomyosarcoma (a) with focal coexpression of synaptophysin (b) and chromogranin A (c) 
802
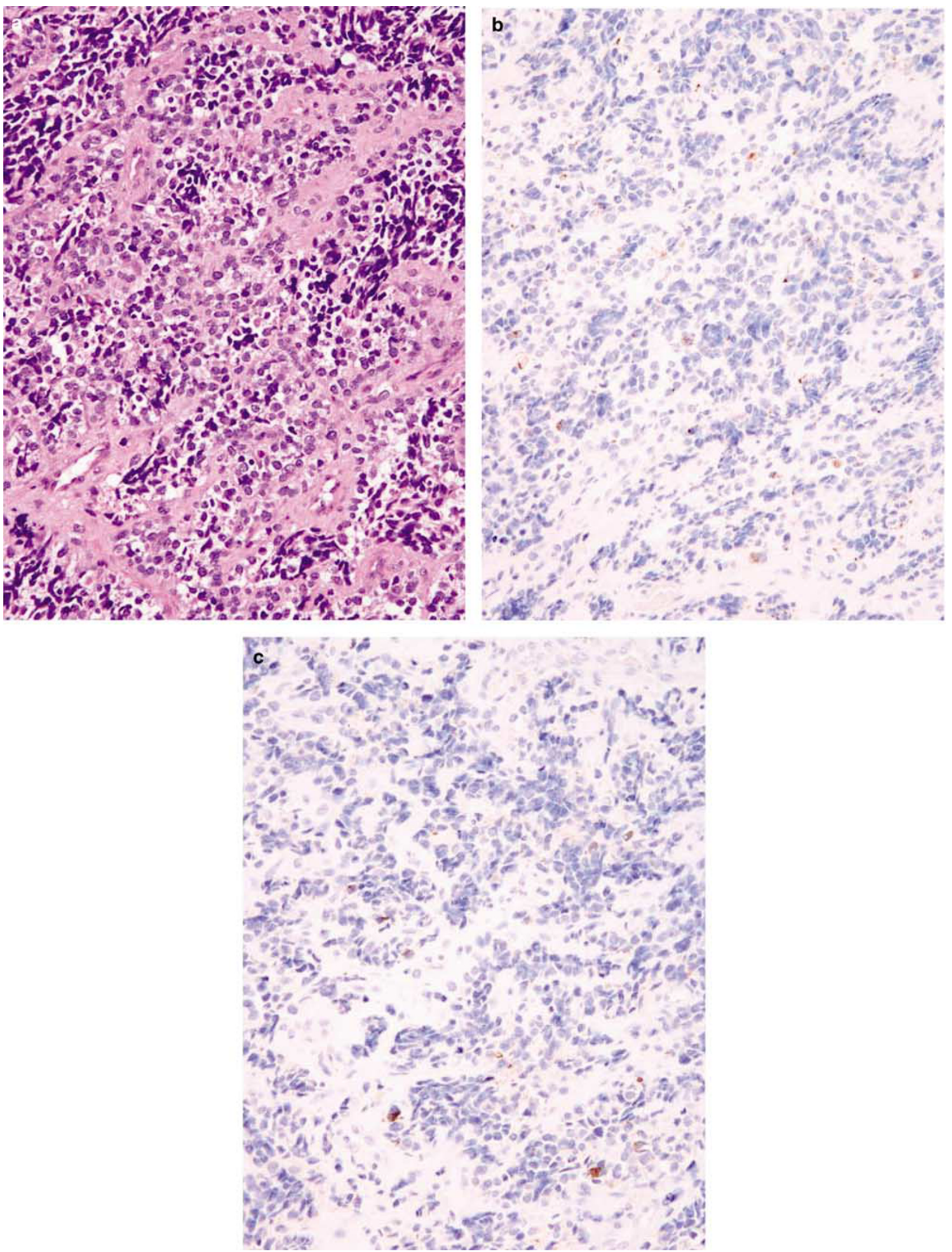

Figure 4 Alveolar rhabdomyosarcoma (a) positive for wide-spectrum cytokeratin (b) and focally positive for synaptophysin (c). 
focal expression of low-molecular weight cytokeratins may be seen in nearly $25 \%$ of Ewing sarcoma/primitive neuroectodermal tumors. ${ }^{38,43,47}$ Only a small number of cytokeratin-positive alveolar rhabdomyosarcomas have been previously reported, with Miettinen et al observing a small number of cytokeratin-positive cells in eight of 12 alveolar rhabdomyosarcomas studied, ${ }^{27}$ and Coindre et al reporting focal cytokeratin expression in primitive cells in three of 60 (5\%) of rhabdomyosarcomas of both alveolar and embryonal types. ${ }^{48}$ Our findings suggest that anomalous cytokeratin expression in alveolar rhabdomyosarcoma may be far more common than has been previously realized.

Synaptophysin, a transmembrane glycoprotein component of the presynaptic vesicle, functions as a membrane channel protein. ${ }^{49}$ In normal tissues, synaptophysin is confined to neural and neuroendocrine cells, and is not expressed in mature skeletal muscle. ${ }^{49}$ In the area of small round cell tumors, synaptophysin expression is generally thought of as being restricted to tumors showing neural or neuroendocrine differentiation, including esthesioneuroblastomas, differentiating neuroblastomas, small cell carcinomas, and Merkel cell carcinomas. ${ }^{50}$ Synaptophysin expression is uncommon in tumors of the Ewing sarcoma family and is generally considered as evidence of a tumor closer to the 'primitive neuroectodermal tumor' end of that biologic continuum. ${ }^{51}$ 'Anomalous' synaptophysin expression is extremely unusual, but may be seen in extraskeletal myxoid chondrosarcomas ${ }^{52,53}$ and very rarely in melanoma. ${ }^{54}$ It is also important to realize that synaptophysin expression may be seen routinely in tissues and tumors not typically thought of as 'neuroendocrine', specifically adrenal cortex and its neoplasms. We are aware of only a single previous case of aberrant synaptophysin expression in alveolar rhabdomyosarcoma, a sinonasal alveolar rhabdomyosarcoma very recently reported by Leroy et $a l^{55}$

Chromogranin A, a calcium-binding protein located in the dense core granule of neural and neuroendocrine cells, shows a similar pattern of distribution in normal tissues as does synaptophysin. ${ }^{49}$ Similarly, chromogranin A expression is very limited among small round cell tumors, being confined to esthesioneuroblastomas, differentiating neuroblastomas, and small cell carcinomas, including Merkel cell carcinoma. ${ }^{49}$ Ewing family tumors only show chromogranin A expression in extremely rare instances. ${ }^{51}$ Unlike synaptophysin, chromogranin expression is not seen in adrenal cortical neoplasms. The synaptophysin-positive alveolar rhabdomyosarcoma previously reported by Leroy et al was also reported to be positive in rare cells for chromogranin $A,{ }^{55}$ lending credence to our findings of coexpression of these markers in a small minority of cases.
CD56 is an integral membrane glycoprotein that mediates calcium-independent homophilic cell-cell binding. ${ }^{56,57}$ CD56 is expressed by many normal cells and tissues, including neurons, astrocytes and glia, adrenal cortex and medulla, renal proximal tubules, follicular epithelium of the thyroid, gastric parietal cells, cardiac muscle, regenerating and fetal skeletal muscle, pancreatic islet cells, human natural killer cells, a subset of $\mathrm{T}$ lymphocytes and peripheral nerve. ${ }^{58-60}$ CD56 may be expressed by a variety of sarcomas, including synovial sarcoma, malignant peripheral nerve sheath tumor, leiomyosarcoma, chondrosarcoma, and osteosarcoma. ${ }^{61-63}$ Although CD56 has been touted as a highly sensitive marker of poorly differentiated neuroendocrine carcinomas, it should be noted that it may also be expressed in nearly all other small round cell tumors (with the possible exception of Ewing sarcoma/primitive neuroectodermal tumor), including nearly all alveolar rhabdomyosarcomas, neuroblastomas, poorly differentiated synovial sarcomas, Wilms tumors, and mesenchymal chondrosarcomas. ${ }^{62-64}$ Our results of near-ubiquitous CD56 expression in alveolar rhabdomyosarcoma are in keeping with these prior findings, and emphasize the non-specificity of this reagent, particularly in clinical scenarios in which small cell carcinoma, rather than alveolar rhabdomyosarcoma, is suspected.

The most important implication of our findings is the potential for misclassification of alveolar rhabdomyosarcoma with other tumors that may share cytokeratin and/or neuroendocrine marker expression. In children and young adults, and in extremity locations, alveolar rhabdomyosarcoma with anomalous immunophenotypes are most likely to be confused with desmoplastic small round cell tumor and Ewing sarcoma/primitive neuroectodermal tumor. In adults, and in head/neck locations, alveolar rhabdomyosarcomas are more likely to simulate small cell neuroendocrine carcinoma, sinonasal undifferentiated carcinoma, and esthesioneuroblastoma. Although desmoplastic small round cell tumor most often occurs in the abdomen of young adults, it may occur in other soft tissue locations and in children. Desmoplastic small round cell tumor may closely mimic cytokeratin-positive alveolar rhabdomyosarcomas by virtue of its similar cytology, nested growth pattern, and frequent coexpression of cytokeratins, desmin and vimentin. Unlike alveolar rhabdomyosarcoma, however, desmoplastic small round cell tumor lacks expression of myogenin/ MyoD1, and contains at the genetic level a specific $\mathrm{t}(11 ; 22)(E W S / W T 1)$ fusion gene. ${ }^{65}$ Although desmoplastic small round cell tumor frequently expresses the non-specific 'neural' markers such as CD56 and neuron-specific enolase, it lacks expression of synaptophysin and chromogranin A. Ewing sarco$\mathrm{ma} /$ primitive neuroectodermal tumors occur in similar age groups and locations as does alveolar rhabdomyosarcoma, and may also show a prominent 
nested growth pattern, although well-developed fibrous septa are not typically present. Although most Ewing sarcoma/primitive neuroectodermal tumors are characterized by the expression of CD99 and Fli-1 protein in the absence of other markers, expression of cytokeratins and desmin may be seen in up to 25 and $3 \%$ of Ewing sarcoma/ primitive neuroectodermal tumors, respectively. ${ }^{38}$ It is important to recognize that CD99 is frequently expressed by alveolar rhabdomyosarcoma, ${ }^{66}$ whereas Fli-1 protein expression has not yet been reported in these tumors. ${ }^{67,68}$ As with desmoplastic small round cell tumor, the absence of myogenin/MyoD1 expression and the presence of different specific fusion genes, most often EWS/FLI-1 or EWS-ERG, serves to distinguish Ewing sarcoma/ primitive neuroectodermal tumor from alveolar rhabdomyosarcoma. ${ }^{69}$

The greatest potential for the misdiagnosis of cytokeratin and/or neuroendocrine marker-positive alveolar rhabdomyosarcoma is in head and neck locations, particularly in adult patients. In this setting, the possibility of alveolar rhabdomyosarcoma is frequently not considered by either clinicians or pathologists, with the result that desmin and/or myogenin/MyoD1 immunostains are not ordered. Obviously, in this setting, the finding of significant cytokeratin and/or neuroendocrine marker expression will frequently result in the diagnosis of 'carcinoma', to the exclusion of other possibilities. We believe that simple awareness of the possibility of alveolar rhabdomyosarcoma in this clinical setting, and inclusion of desmin and/or myogenin/ MyoD1 in a panel of immunostains, should allow for successful resolution of this differential diagnosis.

A final, extremely rare entity which enters the differential diagnosis of cytokeratin/neuroendocrine marker-positive alveolar rhabdomyosarcoma is 'small cell carcinoma with skeletal muscle differentiation' ${ }^{70}$ There appears to be only four previously reported cases of this entity, which was reported first in a case report by Roncaroli et $a l,{ }^{71}$ and subsequently more completely described in a series of three cases by Eusebi et al. ${ }^{70}$ As described by Eusebi et al, small cell carcinoma with skeletal muscle differentiation consists of two cell types, type A cells showing immunoreactivity for cytokeratins and neuroendocrine markers and at most focal expression of skeletal muscle markers (eg, desmin, myogenin, and so on), and type B cells showing little or no reactivity for epithelial and neuroendocrine markers and diffuse expression of myogenic markers. $^{70}$ Small cell carcinoma with rhabdomyoblastic differentiation does not as yet appear to occur in a favored location, with previously reported cases involving the anorectal junction, skin and subcutis of the buttock, nasal cavity, and bladder. ${ }^{70}$ The exact relationship between this rare entity and alveolar rhabdomyosarcoma with anomalous expression of epithelial/neuroendocrine markers remains to be determined. Although it could be argued that some of the cases in our series might in fact be better considered small cell carcinomas with skeletal muscle differentiation, we did not observe any segregation of expression of epithelial, neuroendocrine, and myogenin markers into defined 'type A' and 'type B' groups. Furthermore, the great majority of our cases occurred in young patients and/or soft tissue locations, where small cell carcinoma would be extremely unusual. Finally, 18 of the cases in our series were known to carry alveolar rhabdomyosarcoma-specific gene fusions, a finding which is currently considered the 'gold standard' for this diagnosis. Conversely, one might question whether those cases reported previously as small cell carcinoma with skeletal muscle differentiation represent in fact alveolar rhabdomyosarcoma with aberrant immunophenotypes, especially as none of the previously reported cases was karyotyped or subjected to molecular genetic analysis for alveolar rhabdomyosarcoma-associated fusion genes. A third, perhaps most appealing hypothesis is that cases such as these represent ends along a spectrum of epithelial, neuroendocrine and rhabdomyoblastic differentiation in a primitive progenitor cell of 'ectomesenchymal' derivation, with pure alveolar rhabdomyosarcoma at one end, alveolar rhabdomyosarcoma with epithelial/neuroendocrine differentiation in the middle, and small cell carcinoma with skeletal muscle differentiation at the other end. Confirmation of this hypothesis must of course await additional study, in particular genetic study of small cell carcinomas with skeletal muscle differentiation.

In conclusion, we have shown aberrant expression of epithelial and neuroendocrine markers in significant subsets of alveolar rhabdomyosarcomas, including genetically confirmed cases. Recognition of this phenomenon and appreciation of the immunophenotypic spectrum of alveolar rhabdomyosarcoma are essential to avoid misdiagnosis of this tumor similar to other types of small round cell tumors. Coexpression of epithelial and neuroendocrine markers in alveolar rhabdomyosarcoma, and expression of multiple neuroendocrine markers in some tumors suggest some capacity of alveolar rhabdomyosarcoma for true epithelial or neuroendocrine differentiation. The relationship of alveolar rhabdomyosarcoma with cases previously reported as 'small cell carcinoma with skeletal muscle differentiation' remains to be determined.

\section{References}

1 Weiss SW, Goldblum JR. Enzinger and Weiss's Soft Tissue Tumors, 4th edn. Mosby: St Louis, 2001.

2 Fletcher CDM, Unni KK, Mertens F, et al. Pathology and genetics of tumours of soft tissue and bone. IARC Press: Lyon, 2002.

3 Enzinger FM, Shiraki M. Alveolar rhabdomyosarcoma. An analysis of 110 cases. Cancer 1969;24:18-31.

4 Caillaud JM, Gerard-Marchant R, Marsden HB, et al. Histopathological classification of childhood rhabdo- 
myosarcoma: a report from the International Society of Pediatric Oncology pathology panel. Med Pediatr Oncol 1989;17:391-400.

5 Newton Jr WA, Gehan EA, Webber BL, et al. Classification of rhabdomyosarcomas and related sarcomas. Pathologic aspects and proposal for a new classification-an Intergroup Rhabdomyosarcoma Study. Cancer 1995;76:1073-1085.

6 Tsokos M, Webber BL, Parham DM, et al. Rhabdomyosarcoma. A new classification scheme related to prognosis [see comments]. Arch Pathol Lab Med 1992;116:847-855.

7 Callender TA, Weber RS, Janjan N, et al. Rhabdomyosarcoma of the nose and paranasal sinuses in adults and children. Otolaryngol Head Neck Surg 1995;112:252-257.

8 Ahmed AA, Tsokos M. Sinonasal rhabdomyosarcoma in children and young adults. Int J Surg Pathol 2007;15:160-165.

9 Parham DM. Pathologic classification of rhabdomyosarcomas and correlations with molecular studies. Mod Pathol 2001;14:506-514.

10 Parham DM, Shapiro DN, Downing JR, et al. Solid alveolar rhabdomyosarcomas with the $t(2 ; 13)$. Report of two cases with diagnostic implications. Am J Surg Pathol 1994;18:474-478.

11 Chiles MC, Parham DM, Qualman SJ, et al. Sclerosing rhabdomyosarcomas in children and adolescents: a clinicopathologic review of 13 cases from the Intergroup Rhabdomyosarcoma Study Group and Children's Oncology Group. Pediatr Dev Pathol 2004;7:583-594.

12 Folpe AL, McKenney JK, Bridge JA, et al. Sclerosing rhabdomyosarcoma in adults: report of four cases of a hyalinizing, matrix-rich variant of rhabdomyosarcoma that may be confused with osteosarcoma, chondrosarcoma, or angiosarcoma. Am J Surg Pathol 2002;26:1175-1183.

13 Cessna MH, Zhou H, Perkins SL, et al. Are Myogenin and MyoD1 expression specific for rhabdomyosarcoma? A study of 150 cases, with emphasis on spindle cell mimics. Am J Surg Pathol 2001;25:1150-1157.

14 Mentzel T, Katenkamp D. Sclerosing, pseudovascular rhabdomyosarcoma in adults. Clinicopathological and immunohistochemical analysis of three cases. Virchows Arch 2000;436:305-311.

15 Dias P, Chen B, Dilday B, et al. Strong immunostaining for myogenin in rhabdomyosarcoma is significantly associated with tumors of the alveolar subclass. Am J Pathol 2000;156:399-408.

16 Cui S, Hano H, Harada $\mathrm{T}$, et al. Evaluation of new monoclonal anti-MyoD1 and anti-myogenin antibodies for the diagnosis of rhabdomyosarcoma. Pathol Int 1999;49:62-68.

17 Rubin BP, Hasserjian RP, Singer S, et al. Spindle cell rhabdomyosarcoma (so-called) in adults: report of two cases with emphasis on differential diagnosis. Am J Surg Pathol 1998;22:459-464.

18 Engel ME, Mouton SC, Emms M. Paediatric rhabdomyosarcoma: MyoD1 demonstration in routinely processed tissue sections using wet heat pretreatment (pressure cooking) for antigen retrieval. J Clin Pathol 1997;50:37-39.

19 Coffin CM, Rulon J, Smith L, et al. Pathologic features of rhabdomyosarcoma before and after treatment: a clinicopathologic and immunohistochemical analysis. Mod Pathol 1997;10:1175-1187.

20 Hollowood K, Fletcher CD. Rhabdomyosarcoma in adults. Semin Diagn Pathol 1994;11:47-57.
21 Cavazzana AO, Schmidt D, Ninfo V, et al. Spindle cell rhabdomyosarcoma. A prognostically favorable variant of rhabdomyosarcoma. Am J Surg Pathol 1992;16:229-235.

22 Seidal T, Angervall L, Kindblom LG. Expression of muscle-specific actins and myosin in light microscopically undifferentiated small and dark cell malignancies of soft tissues. APMIS 1990;98:1105-1112.

23 Jones H, Steart PV, Du Boulay CE, et al. Alpha-smooth muscle actin as a marker for soft tissue tumours: a comparison with desmin. J Pathol 1990;162:29-33.

24 Fisher C. The value of electronmicroscopy and immunohistochemistry in the diagnosis of soft tissue sarcomas: a study of 200 cases. Histopathology 1990;16:441-454.

25 Dias P, Parham DM, Shapiro DN, et al. Myogenic regulatory protein (MyoD1) expression in childhood solid tumors: diagnostic utility in rhabdomyosarcoma. Am J Pathol 1990;137:1283-1291.

26 Carter RL, Jameson CF, Philp ER, et al. Comparative phenotypes in rhabdomyosarcomas and developing skeletal muscle. Histopathology 1990;17:301-309.

27 Miettinen M, Rapola J. Immunohistochemical spectrum of rhabdomyosarcoma and rhabdomyosarcoma-like tumors. Expression of cytokeratin and the 68$\mathrm{kD}$ neurofilament protein. Am J Surg Pathol 1989;13:120-132.

28 Seidal T, Kindblom LG, Angervall L. Myoglobin, desmin and vimentin in ultrastructurally proven rhabdomyomas and rhabdomyosarcomas. An immunohistochemical study utilizing a series of monoclonal and polyclonal antibodies. Appl Pathol 1987;5:201-219.

29 Brooks JJ. Immunohistochemistry of soft tissue tumors. Myoglobin as a tumor marker for rhabdomyosarcoma. Cancer 1982;50:1757-1763.

30 Folpe AL. MyoD1 and Myogenin Expression in Human Neoplasia: a review and update. Adv Anat Pathol 2002;9:198-203.

31 Wang NP, Marx J, McNutt MA, et al. Expression of myogenic regulatory proteins (myogenin and MyoD1) in SRCT of childhood. Am J Surg Pathol 1995;147:1799-1810.

32 Sorensen PH, Lynch JC, Qualman SJ, et al. PAX3-FKHR and PAX7-FKHR gene fusions are prognostic indicators in alveolar rhabdomyosarcoma: a report from the children's oncology group. J Clin Oncol 2002;20:2672-2679.

33 Barr FG, Smith LM, Lynch JC, et al. Examination of Gene Fusion Status in Archival Samples of Alveolar Rhabdomyosarcoma Entered on the Intergroup Rhabdomyosarcoma Study-III Trial: a Report from the Children's Oncology Group. J Mol Diagn 2006;8: 202-208.

34 Nishio J, Althof PA, Bailey JM, et al. Use of a novel FISH assay on paraffin-embedded tissues as an adjunct to diagnosis of alveolar rhabdomyosarcoma. Lab Invest 2006;86:547-556.

35 Miettinen M, Lehto VP, Badley RA, et al. Alveolar rhabdomyosarcoma. Demonstration of the muscle type of intermediate filament protein, desmin, as a diagnostic aid. Am J Pathol 1982;108:246-251.

36 Seidal T, Kindblom LG, Angervall L. Alveolar and poorly differentiated rhabdomyosarcoma. A clinicopathologic, light-microscopic, ultrastructural and immunohistochemical analysis. APMIS 1988;96:825-838.

37 Tsokos M. The diagnosis and classification of childhood rhabdomyosarcoma. Semin Diagn Pathol 1994;11:26-38. 
38 Folpe AL, Goldblum JR, Rubin BP, et al. Morphologic and immunophenotypic diversity in Ewing family tumors: a study of 66 genetically confirmed cases. Am J Surg Pathol 2005;29:1025-1033.

39 Folpe AL, Weiss SW. Ossifying fibromyxoid tumor of soft parts: a clinicopathologic study of 70 cases with emphasis on atypical and malignant variants. Am J Surg Pathol 2003;27:421-431.

40 Fanburg-Smith JC, Miettinen M. Angiomatoid 'malignant' fibrous histiocytoma: a clinicopathologic study of 158 cases and further exploration of the myoid phenotype. Hum Pathol 1999;30:1336-1343.

41 Gray MH, Rosenberg AE, Dickersin GR, et al. Cytokeratin expression in epithelioid vascular neoplasms. Hum Pathol 1990;21:212-217.

42 Tauchi K, Tsutsumi Y, Yoshimura S, et al. Immunohistochemical and immunoblotting detection of cytokeratin in smooth muscle tumors. Acta Pathol Jpn 1990;40:574-580.

$43 \mathrm{Gu} \mathrm{M}$, Antonescu CR, Guiter G, et al. Cytokeratin immunoreactivity in Ewing's sarcoma: prevalence in 50 cases confirmed by molecular diagnostic studies. Am J Surg Pathol 2000;24:410-416.

44 Fanburg-Smith JC, Majidi M, Miettinen M. Keratin expression in schwannoma: a study of 115 retroperitoneal and 22 peripheral schwannomas. Mod Pathol 2006;19:115-121.

45 Ordonez NG. Desmoplastic small round cell tumor: II. an ultrastructural and immunohistochemical study with emphasis on new immunohistochemical markers. Am J Surg Pathol 1998;22:1314-1327.

46 Sredni ST, Neves JI, de Camargo B, et al. Pancytokeratin immunoexpression in Wilms' tumors: a simple approach for understanding tumor epithelial differentiation. Sao Paulo Med J 2004;122:181-183.

47 Collini P, Sampietro G, Bertulli R, et al. Cytokeratin immunoreactivity in 41 cases of ES/PNET confirmed by molecular diagnostic studies. Am J Surg Pathol 2001;25:273-274.

48 Coindre JM, de Mascarel A, Trojani M, et al. Immunohistochemical study of rhabdomyosarcoma. Unexpected staining with S100 protein and cytokeratin. J Pathol 1988;155:127-132.

49 Lloyd RV. Practical markers used in the diagnosis of neuroendocrine tumors. Endocr Pathol 2003;14:293-301.

50 Miettinen MM. Diagnostic soft tissue pathology. Churchill Livingstone: New York, 2003.

51 Shanfeld RL, Edelman J, Willis JE, et al. Immunohistochemical analysis of neural markers in peripheral primitive neuroectodermal tumors (pPNET) without light microscopic evidence of neural differentiation. Appl Immunohistochem 1997;5:78-86.

52 Oliveira AM, Sebo TJ, McGrory JE, et al. Extraskeletal myxoid chondrosarcoma: a clinicopathologic, immunohistochemical, and ploidy analysis of 23 cases. Mod Pathol 2000;13:900-908.

53 Goh YW, Spagnolo DV, Platten M, et al. Extraskeletal myxoid chondrosarcoma: a light microscopic, immunohistochemical, ultrastructural and immunoultrastructural study indicating neuroendocrine differentiation. Histopathology 2001;39:514-524.

54 Eyden B, Pandit D, Banerjee SS. Malignant melanoma with neuroendocrine differentiation: clinical, histological, immunohistochemical and ultrastructural features of three cases. Histopathology 2005;47:402-409.

55 Leroy X, Petit ML, Fayoux P, et al. Aberrant diffuse expression of synaptophysin in a sinonasal alveolar rhabdomyosarcoma. Pathology 2007;39:275-276.
56 Cunningham BA, Hemperly JJ, Murray BA, et al. Neural cell adhesion molecule: structure, immunoglobulin-like domains, cell surface modulation, and alternative RNA splicing. Science 1987;236: 799-806.

57 Edelman GM. Cell adhesion molecules in the regulation of animal form and tissue pattern. Annu Rev Cell Biol 1986;2:81-116.

58 Shipley WR, Hammer RD, Lennington WJ, et al. Paraffin immunohistochemical detection of CD56, a useful marker for neural cell adhesion molecule (NCAM), in normal and neoplastic fixed tissues. Appl Immunohistochem 1997;5:87-93.

59 Chan JK, Sin VC, Wong KF, et al. Nonnasal lymphoma expressing the natural killer cell marker CD56: a clinicopathologic study of 49 cases of an uncommon aggressive neoplasm. Blood 1997;89:4501-4513.

60 Lanier LL, Le AM, Civin CI, et al. The relationship of CD16 (Leu-11) and Leu-19 (NKH-1) antigen expression on human peripheral blood NK cells and cytotoxic T lymphocytes. J Immunol 1986;136:4480-4486.

61 Mechtersheimer G, Staudter M, Moller P. Expression of the natural killer cell-associated antigens CD56 and CD57 in human neural and striated muscle cells and in their tumors. Cancer Res 1991;51:1300-1307.

62 Miettinen M, Cupo W. Neural cell adhesion molecule distribution in soft tissue tumors. Hum Pathol 1993;24:62-66.

63 Garin-Chesa P, Fellinger EJ, Huvos AG, et al. Immunohistochemical analysis of neural cell adhesion molecules. Differential expression in small round cell tumors of childhood and adolescence. Am J Pathol 1991;139:275-286.

64 Folpe AL, Schmidt RA, Chapman D, et al. Poorly differentiated synovial sarcoma: immunohistochemical distinction from primitive neuroectodermal tumors and high-grade malignant peripheral nerve sheath tumors. Am J Surg Pathol 1998;22:673-682.

65 Lae ME, Roche PC, Jin L, et al. Desmoplastic small round cell tumor: a clinicopathologic, immunohistochemical, and molecular study of 32 tumors. Am J Surg Pathol 2002;26:823-835.

66 Stevenson A, Chatten J, Bertoni F, et al. CD99 (p30/32MIC2) Neuroectodermal/Ewing's sarcoma antigen as an immunohistochemical marker. Review of more than 600 tumors and the literature experience. Appl Immunohistochem 1994;2:231-240.

67 Rossi S, Orvieto E, Furlanetto A, et al. Utility of the immunohistochemical detection of FLI-1 expression in round cell and vascular neoplasm using a monoclonal antibody. Mod Pathol 2004;17:547-552.

68 Folpe AL, Hill CE, Parham DM, et al. Immunohistochemical detection of FLI-1 protein expression: a study of 132 round cell tumors with emphasis on CD99positive mimics of Ewing's sarcoma/primitive neuroectodermal tumor. Am J Surg Pathol 2000;24: 1657-1662.

69 de Alava E, Pardo J. Ewing tumor: tumor biology and clinical applications. Int J Surg Pathol 2001;9:7-17.

70 Eusebi V, Damiani S, Pasquinelli G, et al. Small cell neuroendocrine carcinoma with skeletal muscle differentiation: report of three cases. Am J Surg Pathol 2000;24:223-230.

71 Roncaroli F, Montironi R, Feliciotti F, et al. Sarcomatoid carcinoma of the anorectal junction with neuroendocrine and rhabdomyoblastic features. Am J Surg Pathol 1995;19:217-223. 